\title{
Research Paper: A Comparison of Language Features Between Patients With Alzheimer Disease and Their Healthy Counterparts
}

Emad Shokri $^{1}$ (D), Sediqe Safaeyan ${ }^{1}$, Hamide Ghaemi ${ }^{1}$, Simin Alimoradi ${ }^{1}$, Ruhollah Tavakoli ${ }^{1}$, Davood Sobhani-Rad ${ }^{1 *}$

1. Department of Speech Therapy, School of Paramedical Sciences, Mashhad University of Medical Sciences, Mashhad, Iran.

Chtation: Shokri E, Safaeyan S, Ghaemi H, Alimoradi S, Tavakoli R, Sobhani-Rad D. A Comparison of Language Features Between Patients With Alzheimer Disease and Their Healthy Counterparts. Journal of Modern Rehabilitation. 2020; 14(1):33-

38. http://dx.doi.org/10.32598/JMR.14.1.4

http://dx.doi.org/10.32598/JMR.14.1.4

Article info:

Received: 03 May 2019

Accepted: 05 Nov 2019

Available Online: 01 Jan 2020

\section{Keywords:}

Alzheimer Disease, Language problems, Elders

\section{ABSTRACT}

Introduction: Alzheimer Disease (AD) is a neurological disorder associated with the progressive damage of memory and problems in communication and language skills. The examination of language in $\mathrm{AD}$ was less studied; therefore, this research aimed to compare linguistic characteristics between $\mathrm{AD}$ patients and their healthy counterparts.

Materials and Methods: A total of 32 patients with AD (16 women and 16 men) with an Mean \pm SD age of $77 \pm 7.41$ years, and their healthy peers (19 women and 13 men) with an Mean \pm SD age of $81.34 \pm 6.04$ years participated in this study. Both groups were evaluated with the Persian bedside version of western aphasia battery. The results were assessed by the Independent $t$ test. The significance level was set at less than 0.05 .

Results: The mean scores of each test and the general criterion for the adversity quotient index were significant between the two groups $(\mathrm{P}<0.001)$. The highest difference was in continuous and naming indices, and the least difference was seen in the repeat index.

Conclusion: The $\mathrm{AD}$ considerably affects all oral language skills; therefore, patients are significantly weaker than healthy individuals.

\section{Introduction}

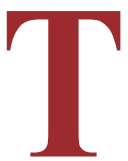

he progressive loss of cognitive function, often associated with age, is called dementia [1], which manifests with a series of symptoms. Patients suffer from impairment in cognitive functions (especially memory) and linguistic, psychological, and psychiatric problems [2], and thus disruptions in daily activities and quality of life [3-5].

The most common form of dementia is Alzheimer disease (AD) [1]. This progressive neurological disorder leads to extensive atrophy of the gray and white matter of the cerebral cortex, due to precipitation and intracellular accumulation of beta-amyloid [6]. Serotonin secretion also decreases significantly in this disease 
[7]. AD consists of three main phases. Its initial (mild) phase is identified with the short-term and middle-term memory loss with different durations. Additionally, fluent speech and word-finding problems and symptoms such as depression and anxiety are often observed [8]. The middle phase (medium) is more severe and longer duration (2-10 years) than in the other two phases. In this phase, patients lose their memory and speech skills and communication, like the ability to answer questions and express thoughts. Also, their ability to do mathematics, read, and write is getting worse [9]. In the final phase (severe), the damage extends to the frontal lobe. As a result, skills such as eating, walking, and recognizing familiar individuals get damaged $[8,10]$. So it is difficult to communicate, and abilities of judgment, logical thinking, and social skills are lost. The duration of this phase is 1-3 years and eventually leads to death.

Clinical diagnosis of $\mathrm{AD}$ follows a logical sequence that includes receiving a biography of a well-informed person, assessing mental status using a valid cognitive function test, and physical examination of vascular and neurological symptoms. One of the useful diagnostic tools is the standardized linguistic test, such as the Persian bedside version of western aphasia battery ( $\mathrm{P}$ WAB-1) [11].

Unfortunately, AD has no definitive treatment, and its incidence doubles every five years after 65 years so that $40 \%$ to $50 \%$ of the elderly over 85 years are affected by AD [12]. It is anticipated that by 2030, 30 million people in the world will have $\mathrm{AD}$ [9], and in 2018, the cost of treatment was $\$ 1$ trillion [13]. In Iran, $10 \%$ of individuals would be above 65 years old by 2035 [14]. Since elderly population is growing rapidly, the prevalence of $\mathrm{AD}$ in Iranian people over 60 years old is estimated as $2.3 \%$ [15]. Therefore, further research in this area seems necessary due to the growing rate of the elderly population, lack of definitive AD treatment, and negative consequences of the disease on the quality of life, including physical, psychological, linguistic, societal, and economic aspects $[5,16,17]$.

Linguistic features are essential areas that have less been noted among AD patients in Iran. Accordingly, this study was performed to evaluate the language skills of Iranian patients with P-WAB-1. It is hoped that with the publication of our results and, consequently, an increase in the knowledge of specialists and patients' relatives, a step is taken towards maintaining health and timely delivery of the necessary services for these patients. This research aimed to compare linguistic characteristics between patients and their healthy counterparts.

\section{Materials and Methods}

\section{Study design}

This research was a descriptive-analytical, cross-sectional, and non-interventional study.

\section{Study participants}

The final size of the sample was calculated as 32 by considering the amount of first and second type error tolerated (in total and in each research group plus the probable duration to reach it), according to a similar study [18], and the mean value formula $(\mathrm{SD}=9.51$, Mean $=37.78$, and accuracy $=0.4$ ):

$$
\frac{\left(z\left(\frac{1-a}{2}\right)\right)^{2} \times S D^{2}}{a \times \text { Mean }}
$$

\section{Study materials}

Accordingly, 32 patients with the diagnosis of AD were randomly selected from the patients visited in hospitals and elderly care centers of Mashhad City, Iran. A consent form was obtained from all patients, and their language skills were assessed by using the P-WAB-1. Besides, 32 healthy individuals who matched the age, gender, and educational status of our test group were selected.

The inclusion criteria for the AD patients, regardless of time constraints and ethical considerations, were diagnosis of AD by a psychiatrist or neurologist, age over 40 years, lack of associated problems such as progressive diseases or other neuropsychological disorders like depression, no history of communicative and linguistic problems, and no history of drug use or care. The neurologist determined the AD phase, too. For the control group, the inclusion criteria included matched peers in terms of age, gender, and academic background, with no history of neurological and psychiatric illnesses or drug use. However, the exclusion criteria were the absence of the patient's collaboration, recurrence of the disease to the degree that prevented the continuation of cooperation, and also other complications and associated illnesses (e.g., anger, lack of communication, severe depression).

\section{Study procedure}

First, we described the study procedure for all participants, followed by receiving written consent forms. Individual sampling was carried out in a quiet environment with sufficient light. The test lasted about 40 
minutes for each participant, containing 5 minutes for resting the patient.

Among the clinical trials for language assessment, Western Aphasia Battery (WAB) is the only test that evaluates three quantitative linguistic-cognitive measures included Aphasia Quotient (AQ), Language Quotient (LQ) and Cortical Quotient (CQ). The AQ indicates severity of aphasia. The LQ is combination of oral and written language scores. Finally, the CQ includes optional nonverbal tests, apraxia, and written language [4].

The Persian version of WAB tests, the P-WAB-1 was used in the current study. The validity and reliability of this test were assessed by Neilipour et al. [11]. P-WAB-1 includes a guide for the implementation of the test, a patient's clinical questionnaire, a clinical version of the test, a visual illustration of the bird nest, and a guide for the evaluation of speech quality and psychology. The test questionnaire section contains all questions the examiner should ask the patient.

The test included six exams of the spontaneous speech content, fluency of spontaneous speech fluency, comprehension of episodes of instruction, auditory comprehension, repetition, and naming. The total score for each exam was 10. After performing the test in a relaxed atmosphere, the scores for each part were collected, and the grades of each person were calculated for each test. Finally, the sum of the exams was divided by 6 and multiplied by 10 . The obtained number was the severity measure or the patient's AQ.

SPSS v. 19 was used for data analysis. The Kolmogorov-Smirnov test was applied to determine the normal distribution of data. Descriptive statistics included calculating mean, standard deviation, minimum, and maximum of the variables. The inferential statistics included calculating the significant difference between the mean of variables between the patient group and the control group by the Independent $t$ test. The significance level was considered as less than 0.05 .

\section{Results}

As presented in Table 1, the proficiency index and its general criterion in $\mathrm{AD}$ patients were higher than those in the healthy individuals, and these differences were significant in all tests $(\mathrm{P}<0.001)$. The benchmark standard for a continuous speech section was an indicator of 20 units. If the standard value of indicators is 10 , the average score of patients with $\mathrm{AD}$ in the continuous speech test (the index of 4.02) is significantly more than the oth- ers. Besides, the section of repetition showed the lowest percentage of frequency.

\section{Discussion}

Our obtained results indicated a significant difference between patients with $\mathrm{AD}$ and healthy individuals in the AQ. The patients were weak in all of its subtests as well as the overall score than the healthy group. Similar to our findings, Roostaiyian and Golbaz found that specific aspects of language and speech abilities were disturbed in $\mathrm{AD}$ patients compared with the healthy subjects $[19,20]$. The results of another study are consistent with our findings regarding the difference in the score of continuous speech. Ripich et al. argued that $\mathrm{AD}$ patients do not correctly use coherence and connectivity in spontaneous speech because their spoken features include very low speech speeds, and they use simple and short sentences [21]. Besides, Jeff et al. indicated that caregivers of the elderly with AD used specific strategies for effective communication with their patients, such as using simple sentences. In contrast, other strategies, such as slow-talking, do not improve the process of communication [22].

In the context of speech comprehension, Grossman et al. concluded that $\mathrm{AD}$ patients had serious disturbances in understanding the meaning of names and verbs. This finding agrees with our results with similar data [23]. Moreover, comparing AD patients with healthy people using neuropsychological tests indicated that patients were a major contributor to semantic systems and that the type of effective guidance in achieving them were semantic cues [22].

Repeating, as an oral language measure, requires proper function of memory because information must first be stored in memory and then be spoken. Our findings indicated that $\mathrm{AD}$ patients suffered when using longer sentences containing more complex words and had a weaker performance. In line with the current results, investigating the mechanisms of attention, decision, and memory in $\mathrm{AD}$ patients suggested that they have weaker performance than healthy older adults [24].

Mehri et al. examined the naming ability of patients with psychotic anxiety and AD by using a language test and reported serious damage in the AD semantic system [18]. The current results confirmed the above report. In general, $\mathrm{AD}$ patients were significantly weaker in all oral language indices. In the continuous speech, examining the skill of defining a subject or an image indicated that these patients were weak, and a considerable differ- 
Table 1. Results of $\mathrm{AQ}$ index of $\mathrm{AD}$ patients and their counterparts and its significance

\begin{tabular}{|c|c|c|c|c|c|c|}
\hline \multirow{3}{*}{\multicolumn{2}{|c|}{ Sections }} & \multicolumn{4}{|c|}{ Mean $\pm S D$} & \multirow{3}{*}{$\mathbf{P}$} \\
\hline & & \multicolumn{4}{|c|}{ Low (High) } & \\
\hline & & $A D$ & HG & $A D$ & HG & \\
\hline \multirow{3}{*}{ Spontaneous speech } & Content & $4.75 \pm 2.25$ & $10 \pm 0$ & $3.93 \pm 5.56$ & $0 \pm 10$ & \multirow{3}{*}{$0.000^{*}$} \\
\hline & Fluency & $3.35 \pm 2.14)$ & $10 \pm 0$ & $2.58 \pm 4.13$ & $0 \pm 10$ & \\
\hline & Total & $8.04 \pm 4.03$ & $19.96 \pm 0.17$ & $6.59 \pm 9.5$ & $19.9 \pm 20.03$ & \\
\hline \multirow{4}{*}{$\begin{array}{l}\text { Auditory comprehen- } \\
\text { sion }\end{array}$} & Question \pm yes, no) & $49 \pm 8.38$ & $60 \pm 0$ & $45.97 \pm 52.02$ & $0 \pm 60$ & \multirow{4}{*}{$0.000 *$} \\
\hline & Words & $44.46 \pm 7.28$ & $60 \pm 0$ & $41.84 \pm 47.9$ & $0 \pm 60$ & \\
\hline & $\begin{array}{l}\text { Episodes of instruc- } \\
\text { tion }\end{array}$ & $46.25 \pm 17$ & $79.5 \pm 0.87$ & $40.11 \pm 52.38$ & $79.18 \pm 79.81$ & \\
\hline & Total & $7.06 \pm 1.03$ & $9.97 \pm 0.04$ & $6.59 \pm 7.53$ & $9.95 \pm 9.99$ & \\
\hline \multirow{5}{*}{ Naming } & Objects & $43.87 \pm 11.9$ & $60 \pm 0$ & $39.55 \pm 48.19$ & $0 \pm 60$ & \multirow{5}{*}{$0.000^{*}$} \\
\hline & Verbal fluency & $7.12 \pm 5.32$ & $19.96 \pm 0.17$ & $5.17 \pm 9.07$ & $19.90 \pm 20.32$ & \\
\hline & Sentences completing & $7 \pm 2.09$ & $10 \pm 0$ & $6.24 \pm 7.75$ & $0 \pm 10$ & \\
\hline & $\begin{array}{l}\text { Responding with one } \\
\text { word }\end{array}$ & $7.46 \pm 2.06$ & $10 \pm 0$ & $6.72 \pm 8.21$ & $0 \pm 10$ & \\
\hline & Total & $6.56 \pm 1.55$ & $10 \pm 0$ & $6.06 \pm 7.12$ & $0 \pm 10$ & \\
\hline \multicolumn{2}{|c|}{ Repeat } & $7.38 \pm 1.55$ & $10 \pm 0$ & $6.82 \pm 7.94$ & $0 \pm 10$ & $0.000 *$ \\
\hline \multicolumn{2}{|c|}{$A Q$} & $58 \pm 11.1$ & $99.88 \pm 0.39$ & $53.99 \pm 62.01$ & $99.7 \pm 100.02$ & $0.000 *$ \\
\hline
\end{tabular}

ence with healthy participants was observed regarding this area.

Another skill that this item examines is the psychological and speech speed, which was far from expected due to weak language skills as well as poor speech organ movement. Other items with a considerable difference were the verbal skills, such as naming objects, verbal fluency, sentence completion, and single-word response. These skills require searching for the word in memory in the shortest possible time and making it into speech. $\mathrm{AD}$ patients had difficulty in these items due to memory weakness and disorientation of the categories.

According to our data, $\mathrm{AD}$ had the least damage on the skill of repetition, probably because this skill requires less processing in language items, and there is no need for a person to find out the words and express their memory. However, sentences became more complex in AD patients, and their main problem was with the long and complex sentences.
$\mathrm{AD}$ is characterized by progressive deficits in several cognitive domains, including language. Language impairment in AD primarily occurs because of a decline in semantic and pragmatic levels of language processing [25].

Based on a review of Steven et al., language impairment in AD primarily results from a decline in semantic and pragmatic levels of language processing. Semantic processing involves language content, such as words and their meaning, and the associated impairments include difficulties with word-finding, naming, and word comprehension, as well as semantic paraphasia (choosing incorrect words), empty speech (using ambiguous referents), inventing words, and loss of verbal fluency. Pragmatic processing goes beyond words and their meaning and concerns language adaptation to the social situation [26].

Examples of pragmatic problems are speaking too much at inappropriate times, talking too loudly, repeating ideas, and deviating from the topic. Deficits in prag- 
matic processing may also be influenced by other $\mathrm{AD}$ symptoms, such as impairments in memory and concentration, and disinhibition. However, it is thought that semantics and pragmatics are interdependent such that semantic deficits in word-finding and naming may contribute to pragmatic problems in maintaining the topic of conversation or may overwhelm the cognitive ability of the patient, resulting in shouting or use of profanity [21].

Although subtle language deficits are detected in the early stages of $\mathrm{AD}$, the mechanics of speech (i.e., phonological and syntactic performance) appear to be well preserved, and at least some of the perceived deficits result from dysfunction in nonlinguistic domains such as attention and executive control. In the early stages of $\mathrm{AD}$, language impairment involves lexical retrieval problems, loss of verbal fluency, and breakdown in the comprehension of higher-order written and spoken languages. In the moderate and severe stages of $\mathrm{AD}$, the loss of verbal fluency is profound, with the breakdown of comprehension and literal and semantic paraphrases. In very severe $A D$, speech is often restricted to echolalia and verbal stereotypy [27].

\section{Conclusion}

Based on the strengths and weaknesses of language abilities in AD patients, a suitable treatment plan must be used not only to preserve available linguistic skills but also to stabilize or even reverse this progressive disorder. Study limitations included lack of access to patient's medical history, lack of cooperation, time limits, and losing the study patients.

\section{Ethical Considerations}

\section{Compliance with ethical guidelines}

The Ethics Committee of Mashhad University of Medical Sciences approved the study (Code: IR.MUMS. REC.1397.128).

\section{Funding}

The research funded by Mashhad University of Medical Sciences (NO. 961275).

\section{Authors contributions}

All authors contributed in designing, running, and writing all parts of the research.

\section{Conflict of interest}

The authors declared no conflict of interest.

\section{References}

[1] Rosenhan DL, Seligman MEP. Abnormal psychology [Y Seyyed Mohammadi, Persian trans.]. 11 ${ }^{\text {th }}$ ed. Tehran: Savalan 2011. http://opac.nlai.ir/opac-prod/bibliographic/593556

[2] Hosseiny RS, Bastani F, Sayahi S, Momen-Abadi A, Alijanpoor-Aghamaleki M. [The effect of educational-counseling program on general health of women as caregivers of patient, with Alzheimerdisease (Persian)]. Journal of Shahrekord University of Medical Sciences. 2011; 13(5):83-92. http://eprints. skums.ac.ir/3980/1/2.pdf

[3] Alzheimer's Association. 2010 Alzheimer's disease facts and figures. Alzheimer's \& Dementia. 2010; 6(2):158-94. [DOI:10.1016/j.jalz.2010.01.009] [PMID]

[4] Sheykhi MT. Aging and the Consequent Alzheimer's Disease in Iran: An Outlook. Journal of Alzheimer's Parkinsonism \& Dementia. 2017; 2(3):1-6. https://scientonline.org/ open-access/aging-and-the-consequent-alzheimers-diseasein-iran-an-outlook.pdf

[5] Norton MC, Dew J, Smith H, Fauth E, Piercy KW, Breitner JCS, et al. Lifestyle behavior pattern is associated with different levels of risk for incident dementia and Alzheimer's disease: The Cache County study. Journal of the American Geriatrics Society. 2012; 60(3):405-12. [DOI:10.1111/j.15325415.2011.03860.x] [PMID] [PMCID]

[6] Soukup JE. Alzheimer's Disease: A guide to diagnosis, treatment, and management. Westport, CT: Praeger; 1996. https://books.google.com/books?id=hKmz4v5E1pcC\&dq

[7] Dash P, Villemarette-Pitman N. Alzheimer's Disease, Demos Medical Publishing. [English] $1^{\text {st }}$ ed. New York; 2005. https:/ / books.google.com/books?id=M1jSCgAAQBAJ\&q.

[8] Staff MC. Alzheimer's stages: How the disease progresses [Internet]. 2019 [Updated 2019 April 19]. Available from: https://www.mayoclinic.org/diseases-conditions/alzheimersdisease/in-depth/alzheimers-stages/art-20048448

[9] Shivanand P. Review on Alzheimer's disease: its cause, symptoms, and treatment at worldwide. International Journal of Applied Biology and Pharmaceutical Technology 2009; 1(1):112-20. http://www.ijabpt.com/pdf/36013-Shivanand-13.pdf

[10] Klimova B, Maresova P, Kuca K. Assistive technologies for managing language disorders in dementia. Neuropsychiatric Disease and Treatment. 2016; 12:533-40. [DOI:10.2147/NDT. S95903] [PMID] [PMCID]

[11] Nilipour R, Pourshahbaz A, Ghoreyshi ZS. Reliability and validity of bedside version of Persian WAB (P-WAB-1). Basic and Clinical Neuroscience. 2014; 5(4):253-8. [PMID] [PMCID]

[12] Agronin ME. Dementia: A practical guide. Philadelphia: Lippincott Williams \& Wilkins; 2004. https://books.google. com/books?id=KuNkQgAACAAJ\&dq 
[13] Katzman R. The prevalence and malignancy of Alzheimer disease: A major killer. Archives of Neurology. 1976 33(4):217-8. [DOI:10.1001/archneur.1976.00500040001001] [PMID]

[14] Ferri CP, Prince M, Brayne C, Brodaty H, Fratiglioni L, Ganguli M, et al. Global prevalence of dementia: A Delphi consensus study. The Lancet. 2005; 366(9503):2112-7. [DOI:10.1016/ S0140-6736(05)67889-0]

[15] Gholamzadeh S, Heshmati B, Mani A, Petramfar P, Baghery Z. The prevalence of Alzheimer's Disease: Its risk and protective factors among the elderly population in Iran. Shiraz E-Medical Journal. 2017; 18(9):e57576. [DOI:10.5812/ semj.57576].

[16] Seyed Mirzaie M. [Some observations on the dimensions of aging with a look at Japan's experience (Persian)]. Journal of Human Sciences. 2007; (53):201-22. https://www.sid.ir/fa/ journal/ViewPaper.aspx?ID=75372

[17] Nanbakhsh F, Mohaddesi H, Amirai A, Haji Shafiha M, Broomand F, Bahadori F, et al. [The effect of health education on elderly weomen life quality (Persian)]. Journal of Payavard Salamat. 2011; 5(1):47-57. http:/ / payavard.tums.ac.ir/article1-85-en.html

[18] Mehri A, Jahani Y, Alemi R, Aramipour E. [Investigation of usage of semantic and phonological cues in naming of fluent aphasia and Alzheimer disease (Persian)]. Audiology. 2007; 16(2):51-6. http://aud.tums.ac.ir/browse.php?a id $=149 \&$ sid $=1 \&$ slc_lang $=$ en

[19] Roostaiyan H. [The study of speech disorders in different stages of Alzheimer's disease (Persian)] [MSc. thesis]. Tehran: Islamic Azad University, Central Tehran Branch; 2007. http://opac.nlai.ir/opac-prod/bibliographic/1118236

[20] Golbaz A. [The study of discourse feature in Alzheimer's disease Persian natives (Persian)] [MSc. thesis]. Tehran: Allameh Tabataba'i University; 2007. https://ganj-old.irandoc. ac.ir/articles/466038

[21] Ripich DN. Functional communication with AD patients: a caregiver training program. Alzheimer Disease \& Associated Disorders. 1994; 8:95-109. [DOI:10.1097/00002093-19940400000011] [PMID]

[22] Small JA, Gutman G, Makela S, Hillhouse B. Effectiveness of communication strategies used by caregivers of persons with Alzheimer's disease during activities of daily living. Journal of Speech, Language, and Hearing Research. 2003, 46(2):353-67. [DOI:10.1044/1092-4388(2003/028)]

[23] Grossman M, Mickanin J, Onishi K, Robinson KM D'Esposito M. Lexical acquisition in probable Alzheimer's disease. Brain and Language. 1997; 60(3):443-63. [DOI:10.1006/ brln.1997.1841] [PMID]

[24] Johnson J, Im $\square$ Bolter N, Pascual $\square$ Leone J. Development of mental attention in gifted and mainstream children: The role of mental capacity, inhibition, and speed of processing. Child Development. 2003; 74(6):1594-614. [DOI:10.1046/j.14678624.2003.00626.x] [PMID]

[25] Ferris SH, Farlow M. Language impairment in Alzheimer's disease and benefits of acetylcholinesterase inhibitors. Clinical Interventions in Aging. 2013; 8:1007-14. [DOI:10.2147/ CIA.S39959] [PMID] [PMCID]
[26] Savundranayagam MY, Hummert ML, Montgomery RJV Investigating the effects of communication problems on caregiver burden. The Journals of Gerontology: Series B. 2005; 60(1):S48-S55. [DOI:10.1093/geronb/60.1.S48] [PMID]

[27] Tang-Wai DF, Graham NL. Assessment of language function in dementia. Geriatrics and Aging. 2008; 11(2):103-10. https://www.medscape.com/viewarticle/573859 